University of Wollongong

Research Online

Faculty of Social Sciences - Papers (Archive) Faculty of Arts, Social Sciences \& Humanities

2015

Technology tools to support learning design: Implications derived from an investigation of university teachers' design practices

Sue Bennett

University of Wollongong, sbennett@uow.edu.au

Shirley Agostinho

University of Wollongong, shirleya@uow.edu.au

Lori Lockyer

University of Wollongong, lori.lockyer@gmail.com

Follow this and additional works at: https://ro.uow.edu.au/sspapers

Part of the Education Commons, and the Social and Behavioral Sciences Commons

Research Online is the open access institutional repository for the University of Wollongong. For further information contact the UOW Library: research-pubs@uow.edu.au 


\title{
Technology tools to support learning design: Implications derived from an investigation of university teachers' design practices
}

\author{
Abstract \\ The need to improve the quality of higher education has fostered an interest in technology tools to \\ support effective design for teaching and learning. Over the past decade this interest has led to the \\ development of tools to support the creation of online learning experiences, specifications to underpin \\ design systems, and repositories to share examples. Despite this significant activity, there remain \\ unanswered questions about what shapes university teachers' design decisions and how tools can best \\ support their design processes. This paper presents findings from a study of university teachers'; design \\ practices that identified teachers' perceptions of student characteristics, their own beliefs and \\ experiences, and contextual factors as key influences on design decisions. The findings extend our \\ understanding of activities fundamental to higher education teaching and inform thinking about design \\ support tools.
}

\section{Keywords}

support, tools, technology, investigation, university, practices, derived, teachers, implications, design, learning

\section{Disciplines}

Education | Social and Behavioral Sciences

\section{Publication Details}

Bennett, S., Agostinho, S. \& Lockyer, L. (2015). Technology tools to support learning design: Implications derived from an investigation of university teachers' design practices. Computers and Education, 81 211-220. 
Technology tools to support learning design: Implications derived from an investigation of university teachers' design practices

Sue Bennett (corresponding author)

School of Education, Early Start Research Institute, University of Wollongong

Northfields Ave, Wollongong, NSW, 2252, Australia

sue_bennett@uow.edu.au

Phone: +61242214637

Shirley Agostinho

School of Education, Early Start Research Institute, University of Wollongong

Northfields Ave, Wollongong, NSW, 2252, Australia

shirley_agostinho@uow.edu.au

Lori Lockyer

School of Education, Macquarie University

Balaclava Road, North Ryde, NSW, 2109, Australia

lori.lockyer@mq.edu.au

\section{Highlights}

- Design is an important, routine part of university teaching, but is poorly supported.

- Technology tools to support teachers design online learning experiences are needed.

- We identify student, teacher and contextual characteristics that influence design.

- These contextualise and extend an existing conceptual model of higher education.

- We discuss the implications for the functionality of technology design support tools. 


\begin{abstract}
The need to improve the quality of higher education has fostered an interest in technology tools to support effective design for teaching and learning. Over the past decade this interest has led to the development of tools to support the creation of online learning experiences, specifications to underpin design systems, and repositories to share examples. Despite this significant activity, there remain unanswered questions about what shapes university teachers' design decisions and how tools can best support their design processes. This paper presents findings from a study of university teachers' design practices that identified teachers' perceptions of student characteristics, their own beliefs and experiences, and contextual factors as key influences on design decisions. The findings extend our understanding of activities fundamental to higher education teaching and inform thinking about design support tools.
\end{abstract}

\title{
1. Introduction
}

Significant resources are invested in initiatives to improve the quality of university teaching through national programs, such as the United Kingdom's Higher Education Academy and Australia's Office for Learning and Teaching, or through teaching-focused units within institutions. Many of these initiatives have focused on encouraging changes in pedagogy that lead to improved student achievement. This is informed by extensive research demonstrating that student-focused approaches to teaching encourage deep approaches to learning that result in high quality learning outcomes (Biggs, 2003; Laurillard, 2002; Prosser \& Trigwell, 1997; Ramsden, 2003).

A more recent strand of research and development also concerned with improving the quality of university teaching is learning design (Conole, 2012; Laurillard, 2012; Lockyer, Bennett, 
Agostinho, \& Harper, 2009). Emerging from educational technology research, learning design has been particularly concerned with how best to support university teachers to design effective online learning experiences for their students. These developments are timely, given higher education's increasing reliance on online technologies to address challenges of access and flexibility (Dahlstrom, Walker \& Dzuiban, 2013). Though relatively new, learning design includes a diverse array of activities, with an emphasis on technology-based tools and technical specifications to support the design process and the creation of online repositories to share good design examples and practices (eg. Agostinho, 2011; Conole \& Culver, 2009; Hernández-Leo et al., 2006; Laurillard, et al. 2013; Masterman \& Manton, 2011; McAndrew, Goodyear, \& Dalziel, 2006; Koper \& Bennett, 2008).

Despite these advances, learning design research and development is still in its infancy. We know much more about architectural, engineering and industrial design and even the closely related field of instructional design. There is still much to learn about how best to develop teachers' existing design practices, at which stages of the design process would support be most helpful, and what forms that support should take. Research is needed to inform the future development of technologies that support design effectively and that are likely to be adopted. The research reported in this paper was conducted to advance understanding of university teachers' design practices to identify activities or influences that support tools could target.

\section{Background}

Learning design focuses on the routine work of university teachers who are responsible for designing effective learning experiences for their students. It is distinct from instructional design in that it is performed by teachers rather than specialist designers. Learning design 
encompasses not only teachers' planning and preparation for interactions with students during a teaching session, but also how they adapt designs in response to student reactions, reflect on improvements to their designs, and share design ideas.

The rationale for learning design support is that improvements to the design of learning experiences can help to improve student outcomes by creating an environment more conducive to effective learning. To do this, learning design (and related approaches such as pedagogical patterns) offer examples with guidance that university teachers can tailor to suit their specific contexts (Lockyer et al., 2009). It is anticipated that through the process of adapting these highly customisable examples to their students, discipline, and institution, university teachers can expand their repertoire of teaching practices. This idea is key to the learning design approach, as it is unlikely that teaching practices will develop if a teacher is merely making superficial changes to a rigid template.

It is important to note that learning design is not a naïve conception that assumes that a good design will somehow guarantee learning, or that learning itself can be pre-designed. Rather, the idea is that 'better' design enhances the opportunities for effective learning. It is this fundamental conception that underpins the development of technologies to support learning design. These include online repositories and communities to share design examples and guidance (eg. Conole \& Culver, 2010) and computer-based design tools that help teachers to build and analyse their designs (eg. Laurillard et al, 2013). A key line of development has included tools that enable designs to run online directly or be imported into learning management systems. 
Despite this progress in building design support tools, more needs to be known about how such tools can best be integrated into university teachers' design practices. There has been limited research into the processes by which university teachers design, what influences the decisions they make, and what supports they use (Goodyear, 2005). By contrast, much more is known about planning and preparation by school teachers (Clark \& Yinger, 1977; Elbaz, 1991; Shavelson \& Stern, 1981). As a result, many university learning design initiatives are based on suppositions about design processes rather than empirical evidence. We need to know more about how university teachers design to advance the development of effective design support tools.

A useful starting point is Stark's (2000) studies of North American college teachers. Stark identified factors causing teachers to modify their intentions during design. Assumptions teachers had about their students and about what it meant to teach in their discipline were found to be the strongest influences on their designs. Stark concluded, however, that her study "fell short of exploring in depth the actual decisions teachers make about the 'form' of instruction", and called for further research into design decisions (Stark, 2000, p. 435). More recent research also highlights the importance of contextual factors, demonstrating that an individual teacher might use both student- and teacher-focused strategies depending on the discipline, class size, year level or teaching space (Bennett, Agostinho, Lockyer, Kosta, Jones, \& Harper, 2008; Norton, Richardson, Hartley, Newstead, \& Mayes, 2005). Institutional policies and practices also affect teachers' designs (Bennett, Thomas, Agostinho, Lockyer, Jones, \& Harper, 2011). This paper reports on work that extends this line of research, focusing specifically on identifying key influences that shape university teachers' design decisions and deriving implications these have for technologies to support design. 


\section{Methodology}

This study used a qualitative approach to explore participants' experiences of design work in university teaching. Participants were recruited through four Australian professional academic organisations via a general email invitation. Participation was limited to discipline-based academics, thereby excluding academics in specialist support units or research-only positions. Respondents were provided with detailed information about the study and asked to respond to several screening questions that allowed for purposive sampling on the basis of four criteria: discipline; year level(s) of students taught; years of teaching experience in higher education; and years of experience in online teaching. From the pool of volunteers, 30 were chosen to represent diversity across the criteria and to include roughly equal proportions of participants across three broad discipline groupings - the Sciences, the Arts and the Professions. Participants from 16 Australian universities, across the spectrum of research- and teachingoriented institutions, were included.

Data was collected through semi-structured interviews of 50 to 90 minutes duration. Most participants were interviewed by telephone, with five interviewed face-to-face. The interview protocol included questions about the participants' teaching contexts (units ${ }^{1}$ taught, year levels, topic areas, and the nature of their department and institution), their conceptions of teaching in their discipline, their approaches to designing new units and revising existing ones, the main influences on their design practices, and the supports they used to assist their design processes. Participants were asked to provide specific examples of recent design experiences, as well as describe their practices more generally. The interview questions were developed from the literature, and were particularly informed by Stark (2000) and Prosser and Trigwell

\footnotetext{
${ }^{1}$ For consistency, the term 'unit' is used to refer to a component of a program of study that leads to the award of a degree. 'Course' is used to refer to the whole program of study.
} 
(1997). All interviews were audio recorded and transcribed. Transcripts were sent to participants so they could check them for accuracy.

In the first stage of analysis, the research team developed a preliminary code set based on initial annotated readings of the data as recommended by Creswell (2012). A separate code was included for 'emerging issues', and additional codes were created using key concepts from the literature and the research questions. An initial analytic framework was created by defining each code, identifying indicative quotes to provide examples for each code, and structuring related codes hierarchically into categories. Text coded under emerging issues was examined and assigned to existing codes or new codes were created and integrated into the framework.

Each interview transcript was assigned to two members of the six member research team and coded independent using qualitative analysis software. The two separate codings of each interview were then compared to locate differences in interpretation. These discrepancies were then discussed by the full research team and used to revise definitions or re-assign data to more appropriate codes. This resulted in the amalgamation of some codes and restructuring of the code hierarchy. This process continued until consensus was reached about the application of the analytical framework and the coding was finalised. This method allowed for $100 \%$ inter-coder reliability to be reached.

Themes were identified through a further analysis of coded data by exploring patterns within and across categories. This process began with the preparation of summaries for each category and the codes within them, including the selection of key quotes. All team members then read the full set of category and code summaries and discussed similarities and 
differences within codes and relationships between codes. Higher level themes were then summarised and checked again by all members of the team until consensus was reached.

\section{Results}

The profiles of the 30 participants are shown in Table 1. Participants with more than 10 years of teaching experience were over-represented compared to earlier stage teachers. This may reflect the fact that participants were recruited through education-focused professional organisations, which may attract discipline-based university teachers later in their careers. Almost all participants had experience teaching face-to-face and online, with three participants also having experience in print-and-post distance education.

Table 1: Teaching profiles of the participants

\begin{tabular}{|c|c|c|c|c|}
\hline $\mathrm{Name}^{\mathrm{a}}$ & $\begin{array}{l}\text { Discipline } \\
\text { group }\end{array}$ & Teaching $^{\mathrm{b}}$ & $\begin{array}{l}\text { Years of } \\
\text { teaching } \\
\text { experience }\end{array}$ & $\begin{array}{l}\text { Delivery method } \\
\text { (Face-to- } \\
\text { face/Online) }\end{array}$ \\
\hline Heidi & Arts & UG \& PG & $<5$ years & Both \\
\hline Steve & Arts & UG \& PG & 5-10 years & Both \\
\hline Kerrie & Arts & UG & $>10$ years & Both \\
\hline Christine & Arts & UG \& PG & $>10$ years & Both \\
\hline Julie & Arts & UG \& PG & $>10$ years & Both \\
\hline Katrina & Arts & UG \& PG & $>10$ years & Both \\
\hline Kirk & Arts & UG \& PG & $>10$ years & Both \\
\hline Shane & Arts & UG \& PG & $>10$ years & Both \\
\hline Trent & Arts & UG \& PG & $>10$ years & Both \\
\hline George & Arts & UG \& PG & $>10$ years & Face-to-face \\
\hline Kathleen & Professions & UG & $<5$ years & Both and Distance \\
\hline Cameron & Professions & UG \& PG & 5-10 years & Both \\
\hline Bill & Professions & UG & $>10$ years & Both \\
\hline Joyce & Professions & UG & $>10$ years & Both \\
\hline Lily & Professions & UG & $>10$ years & Both \\
\hline Patricia & Professions & UG & $>10$ years & Both \\
\hline Paul & Professions & UG & $>10$ years & Both \\
\hline Craig & Professions & UG \& PG & $>10$ years & Both \\
\hline Michelle & Professions & PG & $>10$ years & Both \\
\hline Sally & Sciences & UG \& PG & $<5$ years & Both \\
\hline Darren & Sciences & $\mathrm{UG}$ & 5-10 years & Both \\
\hline Debbie & Sciences & UG & 5-10 years & Both \\
\hline Belinda & Sciences & UG & $>10$ years & Both \\
\hline
\end{tabular}




\begin{tabular}{|c|c|c|c|c|}
\hline Name $^{\mathrm{a}}$ & $\begin{array}{l}\text { Discipline } \\
\text { group }\end{array}$ & Teaching $^{\mathrm{b}}$ & $\begin{array}{l}\text { Years of } \\
\text { teaching } \\
\text { experience }\end{array}$ & $\begin{array}{l}\text { Delivery method } \\
\text { (Face-to- } \\
\text { face/Online) }\end{array}$ \\
\hline Gloria & Sciences & UG & $>10$ years & Both \\
\hline Richard & Sciences & UG & $>10$ years & Both \\
\hline Nigel & Sciences & UG & $>10$ years & $\begin{array}{l}\text { Online and } \\
\text { Distance }\end{array}$ \\
\hline Terence & Sciences & UG & $>10$ years & $\begin{array}{l}\text { Online and } \\
\text { Distance }\end{array}$ \\
\hline Deidre & Sciences & $\mathrm{UG} \& \mathrm{PG}$ & $>10$ years & Both \\
\hline Kurt & Sciences & UG \& PG & $>10$ years & Both \\
\hline Lola & Sciences & UG \& PG & $>10$ years & Both \\
\hline
\end{tabular}

${ }^{a}$ Pseudonyms have been used. ${ }^{b} \mathrm{UG}=$ Undergraduate, $\mathrm{PG}=$ Postgraduate

The analysis revealed three main types of influences that shaped learning design as described by the participants: the characteristics and responses of their students; their own beliefs and experiences; and factors emerging from their particular contexts.

\subsection{The characteristics and responses of students}

Designing units that meet the needs of their students was a consistent theme across the interviews. It was also evident that participants developed a sense of 'who their students were'. Notably some spoke about approaching learning design by considering students' interests; for example "One of the first things I think about is... what are the students going to find engaging" (Belinda, Sciences). Trent (Arts) explained, "I've been trying to understand these students as much as possible for a number of years, so what I try to do is tailor the resources and the activities around their interests or their motivations." This deliberate effort to 'get to know' students was a consistent theme.

Many participants spoke in terms of general characteristics of their students; for example, describing the different needs of international and domestic students, on-campus and offcampus students, undergraduate and postgraduate students, male and female students. 
Participants' comments give a sense of them developing an understanding of how best to teach the types of students likely to be enrolled in their units:

There are gender differences. I think some of the boys are still emerging adults and so...if they're going to be school teachers... they need to become more articulate and to reflect a little bit more and to interact with others. (Paul, Professions)

We have to prioritise much more because this is the only chemistry a lot of these students are going to be doing. They are going to be going on to do food sciences, forensic science and other areas where they're not going to get further chemistry. (Richard, Sciences)

When I teach the third-year elective subject, I know that the number of students is very small, but those few are very interested in the details and are focused on what is ... expected.... I go into much more detail than, say, a first-year subject. (Cameron, Professions)

You see a huge shift in intrinsic motivation to learn as you work closely with postgraduate students. Postgrads are usually very strong in intrinsic motivation, so they're very easy to work with. (Shane, Arts)

These responses suggest that over time these teachers developed general ideas about what they 'knew' about particular cohorts of students. This is not to say they necessarily stereotyped their students, but that observing the characteristics of cohorts over time enabled 
teachers to anticipate the types of students they would be teaching and adjust their learning designs accordingly.

Designing to the needs of students went beyond the particular learning outcomes of a unit, with many considering what students required more generally to be prepared in a discipline or for a profession. This sentiment is clearly expressed in the following comment:

Undergraduates are very challenging because sociology really is about reading and writing and thinking. If we're not able to create and encourage that routine so it's something that students just deal with as a matter of habit, then I think the possibilities of deep learning are limited. (Shane, Arts)

As might be expected, a majority of participants (17 of 30) mentioned that student feedback often prompted them to rethink particular areas of their teaching. Sometimes this was informal feedback, such as a comment in class by a student; for example, "The postgraduate students come up with some really funky things" (Diedre, Sciences). Feedback also came through formal teaching evaluations administered by the institution: "Students have to evaluate every unit every semester that they take, so we get [feedback] from that" (Joyce, Professions).

In addition to what they were able to glean directly from student feedback, participants described making judgements about whether students were achieving anticipated or desired outcomes as the principal measure of the success of their design, for example: 
I usually look at the work and I would then actually use that to say - look, I'm not seeing the sort of engagement with professional standards that I would have hoped, and then I would look to try and emphasise that next time around or give them more time for that. (George, Arts)

These observations occurred as assessments were marked and on reflection at the end of a teaching session, with teachers refining their designs over time on the basis of students' experience as their indicator of the quality of student learning:

I learn as much from my students as they learned from me. Their experience of my teaching gives me probably as many ideas about how to adjust and change and adapt that teaching as any formal [evaluation] process or professional development or literature. (Debbie, Sciences)

In summary, these university teachers built up a profile of their students over time. They identified the needs of their students by their perceived characteristics, their academic performance and feedback. This information influenced how teachers designed their units and how they adapted those designs to suit the evolving profile of their students.

\subsection{Teachers' beliefs and expertise}

The participants interviewed explained how their personal beliefs about learning significantly influenced their designs. For some, their general ideas about what makes learning effective were critical: "Learning should be fun, [students] should enjoy the journey, the process of getting their degree as much as the end result and the opportunities that it provides for them" 
(Debbie, Sciences). This was tempered by other responses that recognised that learning should not be made too easy because students need to be challenged:

[I] want my students to know that I'm not there to do the course for them and sometimes learning is difficult. And sometimes their expectations of me won't be met or [their expectations about] the course won't be met, and I think that's about... getting people to take responsibility for their own work. (Shane, Arts)

Few participants described their designs as being underpinned by theories of learning. For example, one said, "I have a theoretical approach to learning, and so there is a theoretical model that I use" (Richard, Sciences). For the most part, they spoke more of their personal beliefs about how students learn best, for example: "I'd say primarily my beliefs about the best way to teach, and my beliefs about how students learn best and what they need to learn" (Patricia, Professions). Beliefs about teaching and learning were described as selecting ideas from educational theories that 'made sense', rather than adhering to one approach. This reluctance to limit oneself to one particular theory is expressed in the following quote:

I've never been able to really lock myself into one area, but I think one of the big things is knowing that it's a sort of constructivism in the sense that the students build their own knowledge. (Belinda, Sciences)

Teaching experience was cited as an important foundation for design. This was most obvious in the iterative re-design of an existing unit, which was more common than designing a unit from scratch. Re-designing was explained by participants as part of a continuous cycle of 
improvement, with units almost never being taught in exactly the same way twice. As Kirk (Arts) put it, "You're basically going off the back of what did and didn't work in your experience". This reflective practice was an integral part of design work for these university teachers.

Participants also described being receptive to new design ideas, and looking for opportunities to innovate and develop their practice. This disposition is illustrated by Craig (Professions), who explained, "I'm comfortable trying new things". Another participant described himself as “making an attempt to engage, or to integrate technology, [even though] that wasn't part of the agenda when we had the degree accredited" (Paul, Professions).

Developing their teaching expertise was an important source of new ideas for participants. For some, their design ideas had been developed through formal training in tertiary teaching:

I then did a Graduate Certificate in Higher Education, and all those experiences made me realise there is more to teaching and there is also more to just standing up there and delivering a polished performance. (Lola, Sciences)

This reflects the trend for university teachers to complete teaching qualifications, sometimes as a probationary requirement for a new appointment. Some participants had extended this into further study or as part of scholarly activity:

I do my $\mathrm{PhD}$ on teaching and learning tools so that is actually...having a large impact on the way I design. (Belinda, Sciences) 
I've found in feedback and in focus groups from what I've researched that students have talked about how they remember stuff if it's more entertaining or there's an anecdote attached to it. (Kirk, Arts)

This reflects the contemporary university environment, in which the scholarship of teaching has become increasingly prominent for discipline-based university teachers and has become an influence on pedagogical design for some.

Prior experience beyond teaching, training, and scholarly activities also influenced design thinking. In the professions, being able to draw on industry experience was a clear priority: "I have worked out in industry as well so there's drawing on my experiences, real-life experiences" (Joyce, Professions). This brings with it a particular perspective:

Perhaps because I've come from industry I look at some of the assessments with more industry eyes, and I'm probably trying to make them academically rigorous, but also [have] in mind that [students] need to be going out there and being able to do certain jobs or tasks that their employers will expect them to be able to do. (Kathleen, Professions)

Participants also emphasised the importance of drawing on their research interests and experience to inform the design of their subjects; for example:

My ideas for the actual content of the discussion about South-East Asia will come from my own research and what I think are the sort of important and embracing 
debates in the area. So it comes from my own research and my own reading in the area. (Heidi, Arts)

Obviously my own personal interests play a big a role, and I think it's important for units to some degree to reflect the person who's teaching them. (Steve, Arts)

These comments give insights into how university teachers see designing as being about 'putting their own stamp' on a unit. This might mean presenting a topic about which they are passionate, sharing their insights from professional experience, or engaging students with a line of reasoning from their research. These preferences are coupled with the experience derived from reflecting on their teaching successes and failures.

Developing teaching expertise also came through engagement with research and scholarly literature. This was highlighted as a key source for new design ideas, described variously as "more or less like a hobby that I'm self-educated in" (Paul, Professions) or as part of a personal reflective process of "immersing myself in the literature" (Michelle, Professions). The following comments give insights into the variety of sources a university teacher might draw upon:

I'm expanding my reading of medical reviews and nursing reviews...that's just sort of an incidental thing.... I'm reading a little bit of educational literature and I've been going to some educational meetings, so just, for example, at the moment, I'm reading about communities of practice. (Darren, Sciences) 
I still do look at literature, I still attend education conferences, I still read education journals. But what I'm looking for is those innovative approaches. (Debbie, Sciences)

These comments give the impression that engagement with literature is ongoing, but unsystematic, as university teachers 'dip into' both discipline-specific and broader educational literature. Other participants, too, spoke of how they drew on popular media and broader life experiences to inspire their designs. This further quote, for example, shows how ideas can come from beyond the institution and outside academia:

I get a lot of ideas by looking at the kind of roles that people might engage in. So, for example, even seeing someone's workplace in a film might give me an idea for a piece of assessment. How could I extrapolate that to a learning situation? And I'm a little bit of a nerd I think because [in] every aspect of my life I find opportunities to say "that would make a great topic or a great assignment." (Debbie, Sciences)

In sum, a range of intrinsic factors influenced university teachers' design decisions. Beliefs about how students learn, the development of their own knowledge and skills as a teacher, and their teaching experiences over time are key influences on how these university teachers thought about and enacted the design of their units.

\subsection{Influences emerging from the context}

The collegial context in which university teachers work emerged as a strong influence on design decisions. As one put it, "a lot of us talk about these sort of things all the time" (Craig, Professions). For the most part these discussions were described as serendipitous informal conversations, for example "chatting in the corridors" (Patricia, Professions). The following 
comment provides a good illustration of the range of conversations one university teacher had engaged in:

I never give a unit outline to a student until it's been through a peer review process with this group of colleagues. And they provide me with enormous feedback, even just on grammatical things or explaining instructions. So I do get a lot of ideas by talking to them, not necessarily in any formal way. It's just "I've got this unit to do and I was thinking of doing such and such, but that's a bit boring and I'm looking for ideas". It might just be over dinner or whatever. (Debbie, Sciences)

These conversations with close colleagues tended to occur within the organisational unit (the department, school, or faculty). This data demonstrates how design is not only as an individual pursuit, but also a social practice, developed as people within the same context share ideas.

When describing how they approached their design work and the influences on the decisions they made, participants also spoke of working within constraints and needing to make compromises. For each unit they taught, they experienced a different sub-set of demands to which they needed to adapt.

The requirements of the relevant industry were important influences for six of the participants, mostly in terms of what content they needed to include. For some the requirements were explicit; as one participant explained, "the fact is that it is a market-driven course...by that I mean it is shaped by the registration boards across Australia, so they've got that on us" (Bill, 
Professions). In other cases the influence of industry was subtler, as indicated in these two examples:

The [industry boards] don't direct us in the way to go, but we are conscious of what we are doing and how it does impact on the industry. (Craig, Professions)

We have industry input into our courses and to our programs, and we always take note of their suggestions as to how we can improve the course and make it more relevant for the students when they're going out for employment. (Joyce, Professions)

A further set of constraints related to the teaching and learning environment. For example, class size was cited as significant in determining what teaching and learning strategies might be designed for or how effective preferred designs might be:

All pedagogic planning is driven by the numbers you have. So the amount of students I may have in a unit completely dictates whether I can do one thing or another.... The fact is that if you've got 160, 170 students, you can't do certain things. If you have 20 to 30 to 40 to 50 you can do something else. (Kirk, Arts)

Our studio model does not cope with large sizes very well, especially when you need to have a more personal or one-to-one engagement with the students...to some extent we go around that by having them work in groups. (George, Arts)

Timetabling posed further limitations. Participants described themselves working within the structures imposed by timetabled classes. Richard (Sciences) described this challenge as 
needing to optimise opportunities across four different types of classes - lectures, tutorials, practicals, and computer workshops. For some, this inflexibility led to frustrations, as expressed by Darren (Sciences): “I'm pretty sick of giving face-to-face lectures, but I don’t see that there's really much alternative at the moment." The conditions in physical spaces were also limiting. Kirk (Arts) described the challenges he experienced trying to generate discussion in lectures: "You can't really do much in terms of getting them to discuss things themselves when you've got 160 people in the lecture hall".

In units that involved material costs to either the student or the university, teachers explained that the resources available would influence how they designed the unit. For example, Kurt (Sciences) explained that resourcing was "important in driving how I use the different materials". The need to make efficient use of available resources drove what could be done:

In the early years here we had equipment problems. Less so now, but I could never get equipment that I knew should be used in the unit I was teaching... and we didn't have ability to measure things, didn't have the resources, there were no postgrads to assist, and so you cut corners. (Terence, Sciences)

Teaching in an online context created a different set of design considerations. At the most basic level, ensuring equity of access was still a concern, and this influenced the frequency and nature of online interactions designed as part of units. Joyce's experience of adapting a learning activity for students working online exemplifies some of the challenges:

I had the brilliant idea that I would halve the number of tasks, make them more substantial but give them twice as much time...that didn't work because everybody 
was leaving everything until the last minute.... So I then changed it, it was still the same task, but they had mid-point delivery dates. So I was doing part of the time management for them. (Joyce, Professions)

Participants also mentioned workload as influencing their design decisions. In explaining how he adjusted the design according to the workload required, one participant explained, "I have gone down from assessing online discussions from three times to only one because of the load that I have" (Cameron, Professions). These are considerations not just about the workload required to teach that unit, but how the work required fits with a university teacher's other duties. The following comment reflects the balancing act many participants described:

This year I was looking at doing four new units, all outside my area. So that's learning stuff in areas you know nothing about every week to come up with material, and we're supposed to do five hours of teaching each week, as well as HDR supervisions and honours students and so on. It was a case of surviving. (Kirk, Arts)

When talking about these contextual factors, these university teachers gave the sense of being enabled by interactions with colleagues and responding to constraints which were beyond their control. Some of these were discipline-specific, resulting from the need to either explicitly meet accreditation requirements or develop knowledge in students that would be of value in their future employment. Other factors were aspects of the particular institutional and departmental context in which they worked, and the attributes of the unit they were teaching.

\subsection{Summary of findings}


The analysis revealed design as a process by which teachers anticipate the characteristics of their students and respond to various forms of feedback, informed by their beliefs about teaching and their teaching expertise, within the constraints of their particular context. Table 2 summarises the specific key influences on teachers' design decisions identified from the results.

Table 2: Key influences on teachers' design decisions

\begin{tabular}{|c|c|c|}
\hline Focus & Code & Description \\
\hline \multirow[t]{3}{*}{ Student-related } & $\mathrm{S} 1$ & $\begin{array}{l}\text { Teachers perceptions of the students in this unit } \\
\text { (anticipated cohort, influenced by previous experience of } \\
\text { the types of students who enrol in this unit) }\end{array}$ \\
\hline & $\mathrm{S} 2$ & $\begin{array}{l}\text { What students are to learn in this unit within the context of } \\
\text { the program and profession/discipline }\end{array}$ \\
\hline & S3 & $\begin{array}{l}\text { Student feedback and responses during the teaching session } \\
\text { (eg., engagement in class/online, performance on } \\
\text { assessment tasks, feedback and evaluations) }\end{array}$ \\
\hline \multirow[t]{3}{*}{ Teacher-related } & $\mathrm{T} 1$ & $\begin{array}{l}\text { Beliefs about teaching and learning, influenced by theory, } \\
\text { professional learning, others' ideas from literature or } \\
\text { collegial discussion }\end{array}$ \\
\hline & $\mathrm{T} 2$ & Own prior experience of teaching in this and other contexts \\
\hline & $\mathrm{T} 3$ & Beliefs about themselves as a teacher (eg., an innovator) \\
\hline \multirow[t]{5}{*}{ Context-related } & $\mathrm{C} 1$ & Colleagues (within institution, within discipline) \\
\hline & $\mathrm{C} 2$ & Industry/professional accreditation \\
\hline & $\mathrm{C} 3$ & Institutional requirements (policy and culture) \\
\hline & $\mathrm{C} 4$ & $\begin{array}{l}\text { Attributes of the unit (official description, class size, } \\
\text { timetable) }\end{array}$ \\
\hline & $\mathrm{C} 5$ & Resources (eg. staff, workload, time, infrastructure) \\
\hline
\end{tabular}

To contextualise the findings of this study, Figure 1 integrates these influences into the conceptual framework for university teaching and learning proposed by Entwistle and Peterson (2004). The adapted figure elaborates those elements of the framework that specifically relate to "how the design and content of the teaching-learning environment is constructed to support quality learning" (Entwistle \& Peterson, 2004, p. 421). The upper box represents the pedagogy of the unit as designed by the teacher. 


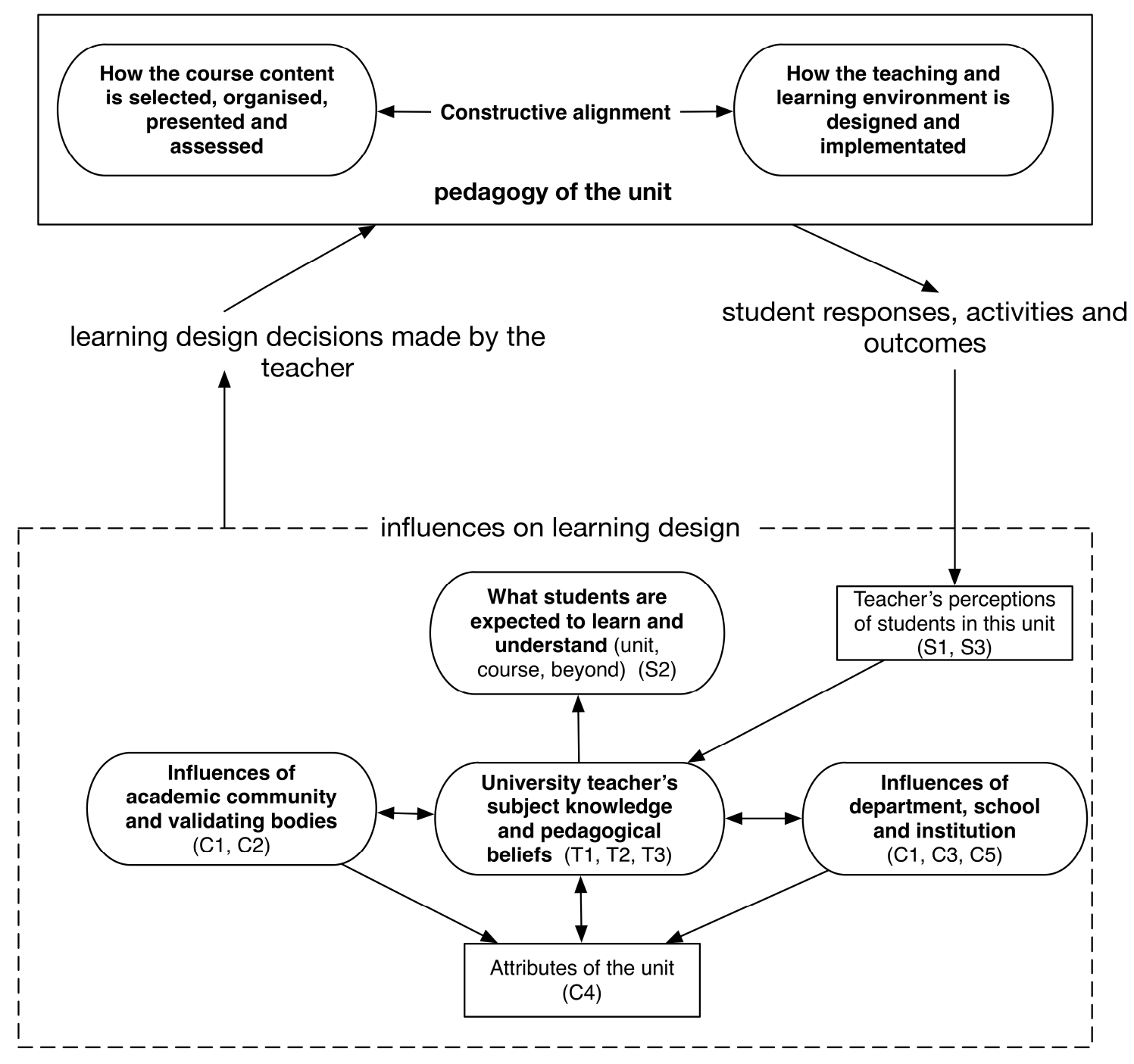

Figure 1: Conceptual framework showing influences on university teachers' decisions about the design of a unit (adapted from Entwistle \& Peterson, 2004, p.421)

The lower box shows the influences that shape the decisions a university teacher makes about the design of a unit. These include the elements identified by Entwistle and Peterson (2004) in bold, which have been related to the key influences identified in this study according to the codes listed in Table 2. Two influences have been added to highlight their importance in our data. The teacher's perceptions of the students in this unit encompassed both anticipation prior to the teaching session of the students who would enrol in the unit and interpretation of students' actual responses to the unit during session. The arrows indicate how these 
perceptions develop over time and shape the teacher's knowledge, beliefs and perceptions in an ongoing cycle, and may result into adjustments to the design. The attributes of the unit itself have been separated from the broader influence of the institution. Participants in this study described units as having particular characteristics documented in their official descriptions as determined by external bodies and institutional requirements, which were then interpreted and enacted by the teacher as part of the design process. These findings help to elaborate the nature of design work within this existing model of university teaching with important consequences for design support tools.

\section{Discussion}

The aim of this study was to understand what influences university teachers when designing units they teach with a view to determining how support tools might improve their design decisions. The influences identified have important implications for conceptualising the types of design supports that are likely to be most effective.

Like Stark (2000), this study found that participants reported their design decisions to be strongly influenced by the perceived characteristics of their students. Postareff and LindblomYlänne (2008) proposed consideration of students' needs over a university teacher's own interests as distinguishing a learning-focused approach in the 'planning of teaching' phase. This clearly marks understanding of one's students as key to good design, but this also raises questions about the quality of the information university teachers rely on to develop their beliefs about their students. Our findings suggest that these judgements are currently reliant on recollections and impressions built up over time and through contact with students.

Making informed decisions is therefore particularly challenging when teaching an existing unit for the first time or for large enrolment subjects taught by teaching teams. A further 
challenge is created by online and blended approaches that can limit contact between teachers and students. Design support tools could improve teachers' understanding of their students. One way would be to collate institutional data about an incoming cohort as an information source. This could include the previous units the incoming cohort have completed and the results they achieved, and past evaluations of the unit being designed. This is data available within institutional systems, but not always easily accessible or compiled in ways that might inform design decisions. This idea also raises questions about what additional data could be collected to help university teachers improve their knowledge of an incoming cohort and of how well students in a current unit are responding to the design. Learning analytics offers some possibilities for development (Lockyer, Heathcote, Dawson, 2013), though to date much of the work in this area has focused on predictive models of student success and attrition from aggregate data held at the institutional level. Our findings suggest that tools to help teachers analyse student responses generated from their interactions with an implemented design could be particularly powerful.

Decisions were strongly shaped by the ways university teachers conceptualised what their design should achieve for their students. This was most obvious in the ways university teachers preparing students for particular professions described the knowledge and skills they regarded as important, the approaches they chose for teaching and assessment, and the influence of accrediting bodies. But common amongst all of the participants was a strong sense of preparing students beyond the immediate unit outcomes, to think in particular ways that reflect the discipline or profession. Tools to help university teachers identify different levels of learning outcomes and explicitly map them to their design may provide an important support for this aspect of the process. 
The influence of discipline was evident in the ways participants sought support for their design processes and new ideas to inspire them. Disciplinary colleagues within their institutions provided both formal and informal assistance, and networks of colleagues externally were additional sources. Many also consulted the educational literature, particularly scholarly work on teaching in their fields. These findings add weight to Stark's (2000) argument that strategies to improve teaching "should build on, rather than challenge, diverse beliefs of faculty groups that stem from the disciplines" (p. 432). Design support tools could activate familiar design thinking in ways that are mindful of the institutional and disciplinary cultures in which university teachers work, and in ways that extend their repertoire of design and teaching ideas. Some such tools already exist in the form of online repositories of examples shared by other university teachers (eg. Conole \& Culver, 2010; Laurillard, 2012), but perhaps more could be done to build from disciplinary roots and make connections across disciplines using recommender systems or social networking. Tools that extend university teachers' understanding of theory and research evidence underpinning the pedagogical approaches of designs also have potential provided they can be integrated into existing practices.

In addition to offering guidance, design support tools also need to enable flexibility. Our findings demonstrate that design occurs for a particular context, and that contexts vary depending on an array of factors even for an individual university teacher and within a particular institution. Tools that do not presume too much about the nature of the context and the attributes of a unit are likely to be more useful than rigid templates. Flexible tools would allow a university teacher to exercise their professional judgement and personalise a design within a support system. Further, there needs to be a means of supporting flexibility within a design. Postareff and Lindblom-Ylänne (2008) associated planning for flexibility and 
improvisation with a student-focused approach because it allows a teacher to be responsive to student needs and interests. This suggests that design support tools that do not allow for changes 'on-the-fly' may be less attractive to university teachers. This highlights the need for tools to occupy a middle ground between open-ended, unsupported design and templates that offer little scope of customisation and adaptive change.

Immediate plans to develop this particular line of research is focusing on extending data collection to other countries to investigate similarities and differences in the contexts in which university teachers undertake design work. Data has been collected from 30 Canadian academics and analysis is underway. A further study of academics in the United Kingdom has received ethics approval and will commence shortly. This and further expansion will provide essential insights into variations that will ensure any tools developed from this research have the widest possible application. Practical application of these research findings is also planned. Specifically, the findings will be used to develop design guidelines for support tools by identifying activities within the design process at which particular targeted assistance can be provided to university teachers. These guidelines will be published and so made available to developers to create new tools and adapt existing systems.

Overall, the findings from this study suggest significant scope for further research to develop richer and more complete accounts of design work by teachers in higher education. Specifically studies that trace the design of a unit prior to, during and after it is taught, are needed to complement data collected from retrospective interviewing. This data could come from naturalistic studies or simulated design tasks in the tradition of protocol studies (eg. Cross, 2006). Further work is also needed to develop the theoretical basis for learning design. Studies based on Activity Theory and case-based reasoning have been proposed (Bennett \& 
Koper, 2008; Conole, 2008), but studies drawing on social cognitive theory and sociology are also needed to explore social aspects of design given the emphasis academics place on the influence of their colleagues on their design decisions. Additionally, much more needs to be known about the challenges of uptake of design tools, especially what institutional and policy support is required.

Finally, it is important to acknowledge this study's limitations. The participants in this study were motivated to continuously improve their units and develop their teaching practice, both by improving what they were doing and by trying new strategies. They were volunteers recruited through professional associations focused on teaching, and so reflect a particular sub-set of university teachers interested in teaching and may not be representative of the broader population. Nonetheless, all were maintaining research careers and many worked in research-intensive institutions; none could be described as teaching-intensive. This suggests that there is a body of university teachers with a commitment to both research and teaching, and whose existing practices could be optimised and extended by new supports and tools to improve university teaching.

\section{Conclusion}

This paper began by making a case for research into university teachers' design practice to inform design support tools to improve university teaching. The research presented in this paper investigated the influences that shape university teachers' design decisions, revealing the prominence of teachers' conceptions of their students, their beliefs about teaching and learning, and the contexts in which they work. Support tools have most potential to improve design decisions by engaging with the key influences that shape existing design practice. Specific suggestions from this study include improving teachers' knowledge of students, 
sharing practice in ways that acknowledge but extend beyond disciplines, providing guidance about pedagogical theory and empirical evidence, and enabling flexibility in design processes and within designs themselves. The study also highlights significant opportunities for further empirical research to extend theoretical and practical understanding of learning design.

\section{Acknowledgements}

The authors would like to thank Barry Harper, Lisa Thomas and Jennifer Jones who were members of the original research team, and assisted in data collection and analysis. This research was funded by the Australian Research Council through the Linkage Project scheme and our collaborating organization, Janison Solutions (Coffs Harbour, Australia). The findings are reported independent of the funding source. There are no conflicts of interest to be declared. All authors of this manuscript had complete access to the data. This research was conducted under protocols approved by the University of Wollongong Human Research Ethics Committee.

\section{References}

Agostinho, S. (2011). The use of a visual learning design representation to support the design process of teaching in higher education. Australasian Journal of Educational Technology, 27(6), 961-978.

Bennett, S., Agostinho, S., Lockyer, L., Kosta, L. K., Jones, J. \& Harper, B. (2008).

Understanding academics' approaches to design. In J. Luca \& E. Weippl (Eds.), ED-MEDIA 2008 World Conference on Educational Multimedia, Hypermedia \& Telecommunications (pp. 3631-3637). Chesapeake, VA: AACE. 
Bennett, S., Thomas, L., Agostinho, S., Lockyer, L., Jones, J., \& Harper, B. (2011).

Understanding the design context for Australian academics: implications for the future of learning design. Learning, Media and Technology, 36(2), 151-167.

Biggs, J. (2003). Teaching for quality learning at university: What the student does. Ballmoor, UK: Society for Research into Higher Education \& Open University Press.

Clark, C. M., \& Yinger, R. J. (1977). Research on teacher thinking. Curriculum Inquiry, 7(4), 279-304.

Conole, G. (2008). The role of mediating artefacts in learning design. In Lockyer, L., Bennett, S., Agostinho, S., \& Harper, B. (Eds.) (2009). Handbook of Research on Learning Design and Learning Objects: Issues, Applications and Technologies, (pp. 209-227). Hershey, PA: IGI Global.

Conole, G. (2012). Designing for learning in an open world. New York: Springer.

Conole, G., \& Culver, J. (2010). The design of Cloudworks: Applying social networking practice to foster the exchange of learning and teaching ideas and designs. Computers $\&$ Education, 54(3), 679-692.

Creswell, J. (2012). Qualitative inquiry and research design: Choosing among five approaches. Thousand Oaks, CA: Sage.

Cross, N. (2006). Designerly ways of knowing. London: Springer. 
Dahlstrom, E., Walker, J., \& Dzuiban, C. (2013). ECAR Study of Undergraduate Students and Information Technology, 2013. Louisville: Educause. Retrieved from http://www.educause.edu/ecar

Elbaz, F. (1991). Research on teachers' knowledge: The evolution of a discourse. Journal of Curriculum Studies, 23(1), 1-19.

Entwistle, N. J., \& Peterson, E. R. (2004). Conceptions of learning and knowledge in higher education: Relationships with study behaviour and influences of learning environments. International Journal of Educational Research, 41(6), 407-428.

Goodyear, P. (2005). Educational design and networked learning: Patterns, pattern languages and design practice. Australasian Journal of Educational Technology, 21(1), 82-101.

Hernández-Leo, D., Villasclaras-Fernández, E., Asensio-Pérez, J., Dimitriadis, Y., Iván, M., Ruiz-Requies, I. \& Rubia-Avi, B. (2006). COLLAGE: A collaborative Learning Design editor based on patterns. Educational Technology and Society, 9(1), 58-71.

Koper, E. \& Bennett, S. (2008). Learning Design: Concepts. In H. Adelsberger, Kinshuk, J. Pawlowski \& D. Sampson (Eds.). International Handbook on Information Technologies for Education and Training (pp. 133-154). Heidelberg: Springer.

Laurillard, D. (2002). Rethinking university teaching. London: RoutledgeFalmer. 
Laurillard, D. (2012). Teaching as a design science: Building pedagogical patterns for learning and technology. New York: Routledge.

Laurillard, D., Charlton, P., Craft, B., Dimakopoulos, D., Ljubojevic, D, Magoulas, G., Masterman, E., Pujadas, R, Whitley, E. \& Whittlestone, K. (2013). A constructionist learning environment for teachers to model learning designs. Journal of Computer Assisted Learning, 29(1), 15-30.

Lockyer, L., Bennett, S., Agostinho, S. \& Harper, B. M. (Eds.) (2009). Handbook of research of learning design and learning objects: Issues, applications, and technologies. Hershey, New York: IGI Global.

Lockyer, L., Heathcote, E., \& Dawson, S. (2013). Informing pedagogical action aligning learning analytics with learning design. American Behavioral Scientist, 57(10), 1439-1459.

Masterman, E., \& Manton, M. (2011). Teachers' perspectives on digital tools for pedagogic planning and design. Technology, Pedagogy and Education, 20(2), 227-246.

McAndrew, P., Goodyear, P. \& Dalziel, J. (2006). Patterns, designs and activities: Unifying descriptions of learning structures. International Journal of Learning Technology, 2(2/3), $216-242$.

Norton, L., Richardson, J., Hartley, J., Newstead, S. \& Mayes, J, (2005). Teachers' beliefs and intentions concerning teaching in higher education. Higher Education, 50, 537-571. 
Postareff, L. \& Lindblom-Ylänne, S. (2008). Variations in teachers' descriptions of teaching: Broadening the understanding of teaching in higher education. Learning and Instruction, 18, 109-120.

Prosser, M. \& Trigwell, K. (1997). Relations between perceptions of the teaching environment and approaches to teaching. British Journal of Educational Psychology, 67(1), 25-35

Ramsden, P. (2003). Learning to teach in higher education. London: Routledge.

Shavelson, R. J., \& Stern, P. (1981). Research on teachers' pedagogical thoughts, judgments, decisions, and behaviour. Review of Educational Research, 51(4), 4555-498.

Stark, J. (2000). Planning introductory college courses: Content, Context and form. Instructional Science, 28, 413-438. 